\title{
PROGRAM PLAN FOR RESEARCH AND DEVELOPMENT IN SUPPORT OF THORIUM FUEL CYCLE TECHNOLOGIES
}

Compiled and Edited by

F. E. Driggers

T. T. Thompson

September 1977

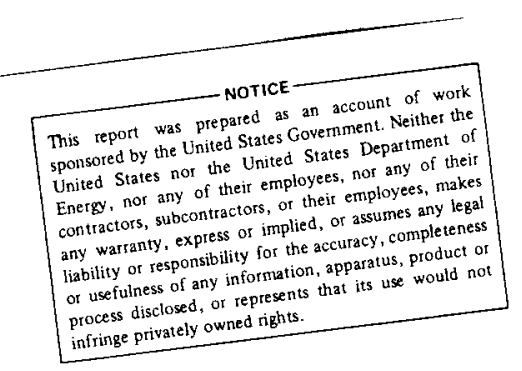

Approved by

L. H. Meyer, Program Manager

E. I. DU PONT DE NEMOURS AND COMPANY SAVANNAH RIVER LABORATORY

AIKEN, SOUTH CAROLINA 29801

PREPARED FOR THE U. S. ENERGY RESEARCH AND DEVELOPMENT ADMINISTRATION UNDER CONTRACT ATIO7-2)-1 


\section{DISCLAIMER}

This report was prepared as an account of work sponsored by an agency of the United States Government. Neither the United States Government nor any agency Thereof, nor any of their employees, makes any warranty, express or implied, or assumes any legal liability or responsibility for the accuracy, completeness, or usefulness of any information, apparatus, product, or process disclosed, or represents that its use would not infringe privately owned rights. Reference herein to any specific commercial product, process, or service by trade name, trademark, manufacturer, or otherwise does not necessarily constitute or imply its endorsement, recommendation, or favoring by the United States Government or any agency thereof. The views and opinions of authors expressed herein do not necessarily state or reflect those of the United States Government or any agency thereof. 


\section{DISCLAIMER}

Portions of this document may be illegible in electronic image products. Images are produced from the best available original document. 


\section{CONTENTS}

\section{$+1$}

Introduction 1

Summary 2

Program Details 3

A. Choice of Design Basis Fuel Cycle 3

B. Status of Technology and R\&D Requirements 3

1. Fuel Receipt and Storage 4

2. Head End Treatment 4

3. Tritium Removal Process 5

4. Dissolving 7

Dissolving - Nuclear Safety 9

5. Off-Gases 10

6. Solvent Extraction 10

Solvent Extraction - Nuclear Safety 11

7. Product Conversion 12

8. Waste Management 13

a. High Level Solid Waste 13

b. Liquid Wastes 15

High Leve1 Liquid Waste (HLLW) 16

Intermediate Level Liquid Waste (ILLW) 17

9. Decontamination/Decommissioning 17

C. Environmental and Safety Studies 18

1. Programmatic Environmental Statement 18

2. Regulatory Aspects 18 ,

3. Environmental Effects 18

D. Economics 19

1. Complete Fuel Cycle Studies 19

2. Processing Plant Studies 19 
E. Proliferation and Safeguards 20

F. Corrosion Studies 21

G. Design Integration Study 21

H. Development Program Schedule 22

References 22

\section{APPENDIX - BACKGROUND INFORMATION 24}

A. Thermal Reactors and Their Fuels 24

1. LWR 24

2. HWR 25

3. SSCR 25

4. HTGR 26

B. Fuel Cycle Alternatives 27

1. Fuel Material 29

2. Cladding 29

3. Fuel Material Form 29

C. LWR Conversion to Thorium Cycle 30

1. Feed Supply 30

2. Fuel Management 30

3. Reactor Facilities 31

4. Regulatory Modifications 31

D. Resource Requirements and Supply 31

References 33 


\section{THE THORIUM FUEL CYCLE TECHNOLOGIES PROGRAM}

\section{INTRODUCTION}

At the request of ERDA, Du Pont initiated the Light Water Reactor (LWR) Fuel Recycle program ${ }^{1}$ in 1975. In the reference design process, uranium and plutonium were to be recovered for recycle in separate streams. Based on current national energy policy, separate recycle of plutonium must be deferred and development of fuel recycle systems must be focused on those systems that reduce the risk of nuclear weapons proliferation. In compliance with this policy, the reference design process for the Alternative Fuel Cycle Technologies (AFCT) Program has been modified so that some of the uranium is recovered and recycled with the plutonium, thus avoiding any pure plutonium process streams. The remaining uranium is recovered and can be reenriched isotopically.

As an extension of the AFCT Program, an evaluation of fuel cycles using thorium has been initiated by ERDA. The Division of Waste Management, Production, and Reprocessing (WPR) has assigned responsibility in the Thorium Fuel Cycle Technologies (TFCT) Program to the following lead organizations:

\section{Thermal Reactors HTGR Fast Reactors}

Fabrication

Aqueous Processing

Pyro or Dry Processing
PNL

$\mathrm{SR}$

ANL
ORNL

ORNL ORNL

ANL $\quad$ ANL

Lead responsibility for both the AFCT and TFCT Programs has been assigned to the Savannah River Fuel Cycle Projects office with Du Pont's Atomic Energy Division responsible for technical management. Research and Development support for these programs will be provided by the ERDA laboratories, appropriate industrial groups, and universities.

The primary goal of the AFCT/TFCT Programs is to develop the technical information required to support future decisions on establishing fuel recycle facilities.

Evaluation will include the identification and performance of the research and development required to produce a fully integrated engineered design study. 
The primary criterion for evaluating thorium fuel cycles is the extent to which the potential for international proliferation of nuclear materials is reduced. Secondary criteria include resource requirements, economics, safety, reliability, environmental impact, technical feasibility, and system schedules.

\section{SUMMARY}

This document describes the portion (to begin in FY-1978) of the Thorium Fuel Cycle Technologies (TFCT) Program to assess aqueous reprocessing of thermal reactor fuel. This program, to be managed by SRL, involves a range of activities, including R\&D to provide aqueous reprocessing technology, conceptual design of an integrated fuel recycle complex (including both aqueous reprocessing and fuel refabrication), and economic assessments. The appendix to this document contains background information for this portion of the TFCT Program.

The aqueous reprocessing RED program and supporting studies will be directed at uncertainties in present technology and the development of new or improved technology, and will include joint programmatic effort by ERDA laboratories and appropriate industries and universities. Details of R\&D studies and required supportive expenditures will be presented in Schedule 189's and topical program documents.

Conceptual designs will be used to develop cost estimates for aqueous reprocessing and fuel refabrication facilities, and will be based on current technology with provision for alterations as advanced technology becomes available from the appropriate R\&D programs. The conceptual design and cost estimate for the reprocessing and refabrication complex will be prepared by the Du Pont Engineering Department.

The selection of an appropriate thorium fuel cycle will involve considerations based on fuel reprocessing as well as fuel fabrication and reactor operation. The design basis thorium fuel cycle will therefore be selected by Savannah River after consultation with those organizations having fabrication and reactor responsibilities. A preliminary selection will be made as a basis for the start of R\&D efforts in October 1977; this selection will be subject to modification later. Proliferation criteria must also be established early, and will similarly be subject to later modifications.

Economic evaluations of thorium fuel cycles will be compared to the uranium throwaway cycle as the reference standard. As proliferation criteria are developed, this reference standard may be altered. 
A programmatic environmental impact statement will be prepared in support of the TFCT Program.

The program schedule allows for reprocessing R\&D efforts beyond FY-1981, with a final Venture Guidance Appraisal* for the aqueous reprocessing and refabrication complex available in February 1981.

\section{PROGRAM DETAILS}

\section{A. Choice of Design Basis Fuel Cycle}

Fuel cycles that are applicable to thorium fueled thermal reactors are described in the appendix. The fuel cycle to be studied in depth will be selected as a cooperative effort among federal agencies responsible for the reactor design (NRA), fuel fabrication (RL) and fuel reprocessors (SR). The initial design basis fuel cycle will be selected prior to October 1977, and will be subject to later modification. In the final analysis the the appropriate fuel cycle will be determined by a cost analysis of a range of alternatives with acceptable proliferation resistances. The analysis will be initiated early in the TFCT Program so that detailed studies can be concentrated on the selected cycle.

Fuel design requirements are usually dominated by the reactor requirements because the reactor is the largest cost component in nuclear power generation and optimization of the reactor and its fuel are of primary importance in assuring $10 \mathrm{w}$ cost power. However, when changes can be made in fuel design that have 1ittle impact on reactor operation but major influence on fuel fabrication and reprocessing, they should be carefully reviewed.

In order to maximize use of existing technology with LWR fuel cycles, a thorium oxide fuel mixed with uranium oxide in denatured form will be assumed for initial studies. Because of the large advantages of zirconium cladding in reactor operation, the studies will assume that zirconium will be used. Both selections may be modified by the design basis fuel cycle selection described above that will be made prior to October 1977 in order to begin RED efforts on that date.

\section{B. Status of Technology and R\&D Requirements}

This section describes the present status and research and development efforts required to describe an aqueous reprocessing plant for the thorium fuel cycle.

* Venture Guidance Appraisal - A cost estimate based on preliminary information which may be used for purposes other than appropriation. 


\section{Fuel Receipt and Storage}

\section{Status}

The technology of water-basin storage of spent fuel is well developed and demonstrated by $\sim 30$ years experience at reactor sites and fuel reprocessing plants. Design and construction capability are available. R\&D is required only for improvements to existing technology. In general, facilities for water-cooled storage of spent fuel consist of near-surface, water-filled cells of heavily reinforced concrete, lined with stainless steel, and having auxiliary equipment to filter the ventilating air and to cool and control the quality of the water. Facilities for receipt of fuel consist of cask handling, cask unloading, and cask cleaning equipment.

Air cooled short term storage is poorly developed, having been demonstrated only for HTGR fuel and some experimental fuels. This type storage is not particularly advantageous for either $\mathrm{UO}_{2}$ or thorium fuel if the fuel is to be reprocessed.

$R \& D$

- Perform process analysis of receipt and storage facilities to optimize design and assess operating risks. This would include shielding and criticality parameter measurements for thorium fuels.

- Develop instrumentation to monitor fuel age and fissile content, and to locate leaking fuel.

- Analyze transportation and handling effects on discharged failed fuel to define the required handling techniques or equipment.

- Develop improved methods to predict long-term stability of spent fuel in underwater storage.

\section{Head End Treatment (Fuel Disassembly)}

\section{Status}

All past and current plans for steel (LMFBR) or zirconium (LWR) clad fuel disassemb1y specify end-piece removal and bundle shearing. Development work has ruled out mechanical disassembly of individual fuel rods from the multi-fuel-rod bundles as an alternative option before shearing. Other decladding methods such as shredding, machining, or laser slitting have been studied and show less promise for commercial application than shearing. 
United States shear technology was developed for Nuclear Fuel Services (NFS) by Oak Ridge National Laboratory. The NFS machine was built by the Birdsboro Company which had no previous nor subsequent experience in fabricating nuclear fuel shears. (There are no experienced fabricators of nuclear fuel shears in the United States.) From 1966 until shutdown of their facility in 1972, NFS sheared 620 tons of irradiated fuel for their shear-leach process. A total of 244 tons of commercial LWR oxide fuel was processed; the remainder was primarily uranium metal fuel from the Hanford $N$ Reactor. The multipurpose shear was capable of handling all LWR fuel being used at the time NFS was operated. NFS has the only experience in the United States with shearing irradiated fuel.

There is some shear experience abroad, particularly in France and Great Britain. Allied General Nuclear Services (AGNS) has a French-made (Saint Gobain Techniques Nouvelles) shear machine in their 1500 ton/year facility. Acceptance tests on the AGNS machine demonstrated it has the capability for shearing simulated LWR fuel bundles as large as 12 inches square; additionally, the AGNS machine is designed to facilitate remote operation and maintenance.

\section{$R \& D$}

The NFS experience indicates that additional shear development is needed in the following areas:

- Remote maintenance of shear-line and auxiliary head-end equipment to sustain high production rates.

- High shear-line cut rates and fuel logistics into and from spent fuel storage area.

- Control of pyrophoricity effects during shearing and cut fuel storage.

Development of improved shearing techniques for LMFBR and LWR fuel bundles is continuing. The technology is applicable to the Th-U fuel assemblies that have similar physical form.

\section{Tritium Removal Process}

\section{Status}

Voloxidation (oxidative heating) was originally designed to remove volatile fission products from sheared LMFBR fuel prior to dissolution. The process has been successfully demonstrated on the laboratory-scale with irradiated Shippingport PWR fuel; 
$99 \%$ of the tritium and $13 \%$ of the ${ }^{85} \mathrm{Kr}$ were volatilized by heating in moist oxygen at $450^{\circ} \mathrm{C}$ for 4 hours. Studies have been limited to rotary kiln tests with unirradiated $\mathrm{UO}_{2}$, and engineering design. Additiona1 laboratory studies and engineering development are required to operate the voloxidation process on a plant-scale.

The removal of tritium from irradiated thoria is likely to be more difficult than with $\mathrm{UO}_{2}$ fuels. The voloxidation process tested with the uranium fuels relies on the change in crystal structure in the oxidation of $\mathrm{UO}_{2}$ to $\mathrm{U}_{3} \mathrm{O}_{8}$ to release tritium as tritiated water at a fairly low temperature $\left(\sim 400^{\circ} \mathrm{C}\right) . \mathrm{ThO}_{2}$ undergoes no such change in crystal structure on heating, and it is anticipated that rather high temperatures may be required for the release of tritium by diffusion through the thoria crystal; such a process may not even work. If the tritium remains in the thoria when it enters the dissolver, it will be highly diluted and its recovery in concentrated form would require a very expensive isotopic separation.

$R \& D$

- Determine economic feasibility of tritium removal from thoria.

- Develop alternative processes for tritium removal (if required), including possible evaluation of grinding the fuel prior to heating to aid tritium removal, and recycle of process solutions for tritium containment.

- Determine optimum temperature, gas velocities, and reaction times for efficient tritium removal while avoiding sintering of fuel.

- Determine effect of tritium removal temperature on $\mathrm{Pu}$ and $\mathrm{Th}$ dissolution.

- Determine heating and cooling requirements for temperature control with fuels of varying irradiation levels.

- Determine possible fire and explosion hazards from zircaloy hulls and fines.

- Select suitable materials of construction to withstand corrosion, abrasion, and high temperatures.

- Determine tritium content of zircaloy cladding and the extent of tritium release from cladding during tritium removal.

- Evaluate batch versus continuous equipment for tritium removal.

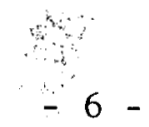


- Determine nuclear safety requirements for the various equipment designs.

- Develop methods for collection of oxide dust from a gas stream and for return to the product stream.

\section{Dissolving}

\section{Status}

No production experience with leach dissolution of sheared fuel has been acquired at SRP or other ERDA sites. However, shear-1each dissolution was practiced by NFS, has also been demonstrated at some foreign sites, and has been incorporated into the design of the AGNS plant at Barnwell.

Both thorium oxide and thorium metal are more difficult to dissolve than their uranium analogs, and fluoride catalysis is required for the dissolution of $\mathrm{ThO}_{2}$ in nitric acid. Even with catalysis the rate is relatively slow. Furthermore, hot $\mathrm{HNO}_{3}$ with HF is aggressively corrosive toward most materials of construction. Consequently, dissolution is likely to be the rate limiting step in thorium processing, and the corrosive nature of the dissolving solutions and the fluoride catalysis are serious problems in designing equipment. Dissolution is known to be accelerated by agitating the solution and by the addition of MgO to the fuel; development of effective techniques for doing this is desirable.

The dissolving rate problem may be further aggravated by the presence of zircaloy cladding in the dissolver. A small amount of data suggests that enough zircaloy will dissolve in the usual dissolver solution (approximately $12 \mathrm{M} \mathrm{HNO}_{3}-0.05 \mathrm{M} \mathrm{HF}$ ) to complex much of the fluoride. This would greatly decrease the dissolution rate of the thoria. If this effect is substantiated, it would indicate that shear-leach processing of zircaloy-clad $\mathrm{ThO}_{2}$ fuels is not practical. It would then be necessary either to develop a decladding method that would not put zircaloy in the dissolver or to use cladding materials such as stainless steel with poorer neutron economy. (Increasing the fluoride concentration to compensate for the zircaloy effect is not practical, because at higher fluoride concentrations $\mathrm{ThF}_{4}$ precipitates are likely to form.)

Alternative reagents for $\mathrm{ThO}_{2}$ dissolution have been considered. Sulfuric acid can be used, but is undesirable in subsequent processing. While breakthroughs in dissolving technology are not likely, there is a big incentive to find improvements. 
Fission products slowly precipitate from dissolved $\mathrm{UO}_{2}$ fuel, forming a highly radioactive fine black precipitate that can be removed by carrying on $\mathrm{MnO}_{2}$ or by flocculating with organic materials. The effect of large Th concentrations on the stability of such solutions needs to be established, and methods for clarifying them tested. A complication in Th solutions is the presence of ${ }^{23} \mathrm{~Pa}$, which will likely carry on any precipitate or deposit on surfaces. This isotope is highly radioactive (27.3d, $\mathrm{B}^{-}$emitter) and yields fissile ${ }^{23} \mathrm{U}$ on decay. It needs to be controlled in order to avoid unexpected accumulations of ${ }^{23} \mathrm{U}$ and to maintain accountability.

Many of the problems listed above require experimental work with irradiated fuel. Such fuel (zirconium clad) is not available, and early irradiation of test materials will be needed to provide experimental material.

$R \& D$

- Determine techniques to dissolve thorium fuel elements and ascertain the effect of fluorides. The determinations will be required for zircaloy, and possibly stainless steel, cladding. Obtain irradiated fuel for experimental work (irradiation of fuel candidates is required).

- Determine the effect of uranium and plutonium oxides on the rate of thorium dissolution in the presence of $\mathrm{MgO}$.

- Determine possible specifications for fuel composition and/or fabrication conditions to promote dissolvability.

- Develop methods of control of possible fire and explosion hazards from zircaloy-clad fuels during dissolution, and during handling before and after dissolution.

- Develop improved methods for monitoring hulls to verify the quantity of fissile material associated with spent hulls prior to disposal.

- Develop methods for dissolving refractory plutonium oxide that may be reproduced by the high temperature used for tritium removal.

- Develop continuous and semicontinuous dissolving processes.

- Develop remote analytical methods to determine $\mathrm{Zr},{ }^{23}{ }^{3} \mathrm{~Pa},{ }^{23} \mathrm{U}$, Th, fluoride, and tritium content in raw dissolver solutions. 
Dissolving - Nuclear Safety

Status

Criticality experiments exist for ${ }^{23}{ }^{3} \mathrm{U},{ }^{235} \mathrm{U},{ }^{232} \mathrm{Th}$ systems, but they are not adequate to validate criticality calculational methods for the dissolving process.

Criticality data for combinations of fertile ${ }^{238} \mathrm{U}$ with fissile nuclides ${ }^{235} \mathrm{U}$ and ${ }^{239} \mathrm{Pu}$ will be provided by the AFCT Program. The TFCT Program will assess the need for, and provide, criticality data for fertile ${ }^{232} \mathrm{Th}$ with fissile nuclides of uranium and plutonium.

There have been criticality experiments on seed and blanket ${ }^{2}{ }^{3} \mathrm{U}-\mathrm{Th}$ oxide lattices with a wide range of enrichments $(2-11 \%$ ${ }^{2{ }^{3}} \mathrm{U}$ in the seed rods and $0.2 \%{ }^{23} \mathrm{U}$ in the blanket rods), but only a limited range of pitches and one rod diameter were used. Another set of lattice experiments is available with $3 \%{ }^{23}{ }^{3} \mathrm{UO}_{2}$ $\mathrm{ThO}_{2}$ lattices that used varying amounts of $\mathrm{H}_{3} \mathrm{BO}_{3}$ as a soluble poison, but these experiments used only one fuel rod diameter (1.27 cm 0.D.).

Homogeneous criticality experiments with ${ }^{23}{ }^{3} \mathrm{UO}_{2}\left(\mathrm{NO}_{3}\right)_{2}$ are available without neutron poisons for moderate-to-large $\mathrm{H} / \mathrm{U}$ ratios (100-2000). Similar experiments with neutron poisons are available only for large $\mathrm{H} / \mathrm{U}$ ratios (1000-2000).

No ${ }^{23}{ }^{3} \mathrm{UO}_{2}-\mathrm{ThO}_{2}$ lattice experiments are available with $\mathrm{HNO}_{3}$ or $\mathrm{UO}_{2}\left(\mathrm{NO}_{3}\right)_{2}$ present. Available lattice and homogeneous experiments are insufficient to determine the minimum ${ }^{23}{ }^{3} \mathrm{U}$ content in $\mathrm{UO}_{2}-\mathrm{ThO}_{2}$ that could be made critical, either with or without neutron poisons.

Criticality calculations of the under-moderated ${ }^{23}{ }^{3} \mathrm{U}$ solutions give results that vary widely depending on the particular cross sections and/or calculational method used. At present, the only way to assure subcriticality of fuel reprocessing systems is to be over-conservative in the design of processing vessels and procedures: this conservatism may cause unnecessary expense either by reducing process vessel volume, and thereby reducing throughput, or by requiring the addition of poisons. Soluble poisons add to the final waste disposal costs. Both soluble and fixed poisons increase the material cost.

$R \& D$

- Determine what data are needed based on the fuel cycle selected for study. 
- Determine the nuclear safety requirements and the need for soluble or fixed neutron poisons. Determinations are usually made with calculations. To minimize the margin necessary to assure subcriticality, the calculational methods and neutron interaction cross sections must be verified against experimental measurements under conditions reasonably similar to those of the process.

These experiments would be performed with (1) under-moderated ${ }^{2}{ }^{3} \mathrm{UO}_{2}\left(\mathrm{NO}_{3}\right)_{2}$ solutions, and (2) $\mathrm{ThO}_{2}-{ }^{2}{ }^{3} \mathrm{UO}_{2}$ lattices in water, $\mathrm{HNO}_{3}$, and in $\mathrm{Th}\left(\mathrm{NO}_{3}\right)_{4} /{ }^{3}{ }^{3} \mathrm{UO}_{2}\left(\mathrm{NO}_{3}\right)_{2}$ solutions; both types of experiments to be done with, and without, soluble and/or fixed neutron poisons. Sufficient data must be obtained from these benchmark experiments to permit verification of calculational methods and neutron cross sections for ${ }^{232}$ Th and ${ }^{23} \mathrm{U}$. Activation ratio measurements should be considered in this connection.

\section{Off-Gases}

\section{Status}

The off-gases from thorium processing are not greatly different from those originating in $\mathrm{UO}_{2}$ processing, although relative quantities may differ. The technology developed for $\mathrm{UO}_{2}$ fuels should apply. A possible complication in plant operation may be the emission of the volatile isotope ${ }^{220} \mathrm{Rn}$, which is not contained by filters. This isotope has only a 55second half-life, but small amounts of its daughters may enter the off-gas stream and constitute a problem of chronic low-level activity releases.

$R \& D$

- Determine applicable off-gas treatment technology for thorium fuels.

- Determine analytical methods to monitor ${ }^{2}{ }^{20} \mathrm{Rn}$ and daughters in off-gas streams.

\section{Solvent Extraction}

\section{Status}

The Thorex solvent extraction process, developed at ORNL and SRL, has been demonstrated at SRP and Hanford. This process must be controlled carefully to avoid third-phase formation; hence, optimization will be required to get maximum throughput of the Th-U mix. 
Much of the development work on solvent extraction will involve the disposition of $\mathrm{Pu}$ formed from the ${ }^{238} \mathrm{U}$ in the fuel. $\mathrm{Pu}$ can be directed to any process stream: Th product, U product, or high activity waste. The choice would depend on Pu content and policy considerations. (A pure Pu stream could also be obtained if desired and permitted.) The behavior of $\mathrm{Pu}$ in Thorex has not previously been demonstrated in detail.

$R \& D$

- Determine the stability of the feed solution toward slow precipitation of fission products.

- Determine the effect of Th on solvent quality and solvent washing.

- Determine the behavior of $\mathrm{Pu}$ in Thorex (if applicable).

- Determine radiation effects on the process.

- Determine behavior of neutron poisons (if applicable).

- Determine methods to reduce the Pu content in streams not intended to contain Pu.

- Develop improved solvent washing methods.

- Develop analytical methods for real-time monitoring of Th, $\mathrm{U}$, and $\mathrm{Pu}$ (if applicable) in process streams.

- Optimize the flowsheet to provide maximum throughput with the generation of minimal quantities of wastes and with a minimum of chemical species (such as sulfate) that complicate waste solidification.

Solvent Extraction - Nuclear Safety

Status

Insufficient data are available on criticality of undermoderated ${ }^{23}{ }^{3} \mathrm{UO}_{2}\left(\mathrm{NO}_{3}\right)_{2}$ solutions with fixed neutron poisons. Reported criticality calculations have large discrepancies between calculations with two different cross section sets and between calculations and experiments. Over-conservative design may be necessary to assure subcriticality of ${ }^{23} \mathrm{U}$ fuel processing. equipment. 
Determine the nuclear safety requirements and the need for fixed neutron poisons. Benchmark experiments are desirable to enable cost effective design of equipment and process for nuclear criticality safety. These experiments can be an extension of those performed for conditions during dissolution.

\section{Product Conversion}

Status

Product streams from the solvent extraction process can conceivably consist of pure uranium, plutonium, and thorium, and/or mixtures of these.

Two conversion routes can be considered for the conversion of a uranium stream containing neither thorium nor plutonium. First, the uranium could be converted to $\mathrm{UF}_{6}$ for isotopic separation (such a process is defined in the AFCT Program although the presence of ${ }^{232} \mathrm{U}$ in the thorium cycle may require a special enrichment facility); following separation, the $U_{F}$ fractions would be converted to $\mathrm{UO}_{2}$ by existing commercial processes. The second option would be to convert the uranyl nitrates to $\mathrm{UO}_{2}$ by any of several routes already used in the power reactor fuel industry. Because of the presence of ${ }^{232} \mathrm{U}$, a shielded facility would be required for either option.

If a pure plutonium stream is isolated, conversion methods already identified in the AFCT Program will be appropriate. The conversion of a pure Th stream will require R\&D effort to further develop existing technology for thoria precipitation and calcination.

In the unlikely event that a uranium bearing stream from solvent extraction contains plutonium, the co-conversion process being developed for the AFCT Program would be appropriate. A uranium/thorium stream could be processed by a co-conversion process similar to the AFCT process, although considerable R\&D effort will be required to determine the effect and compatibility of thorium. If a plutonium/thorium stream is produced, further development of coprocessing methods in the AFCT Program will be required.

$R \& D$

- Define the product streams to be converted, and develop the processes by which conversion can be accomplished. 
- Confirm oxide product merits in pellet fabrication and dissolution tests.

- Establish sources and impact of chemical impurities.

- Develop chemical and physical property specifications for the product oxide powders.

- Establish process parameters for product quality control.

- Develop remote operation and maintenance plan and demonstrate key features in cold mockup facilities.

- Develop backup processes.

- Develop remote analytical methods for on-line $U, T h$, and $\mathrm{Pu}$ assay in mixed oxides.

\section{Waste Management}

\section{a. High Level Solid Waste}

\section{Status}

Solid wastes from a thorium fuel reprocessing plant are expected to be very similar to those from any LWR fuel reprocessing plant. Processing technology (such as decontamination, incineration, and compacting) should be essentially the same and is being developed for the AFCT and other ERDA Programs. Because ${ }^{233} \mathrm{U}$ is defined by ERDA as a transuranic (TRU) isotope for waste management purposes, the amounts and types of TRU waste requiring processing for terminal storage in a federal repository are expected to be about the same for a Th-U cycle as for a U-Pu cycle. However, if $\mathrm{ThO}_{2}$ fuels are clad with stainless steel instead of zircaloy and if the ${ }^{238} \mathrm{U}$ impurity in the stainless steel is low enough that ${ }^{2}{ }^{9} \mathrm{Pu}$ level in the irradiated hulls is $<10 \mathrm{nCi} / \mathrm{g}$ and if surface decontamination of the hulls is thorough, then the hulls might not be classified as TRU waste. This could simplify solid waste management considerably. If, on the other hand, stainless cladding is used and becomes TRU waste, processing technology could be essentially the same as far as zircaloy hulls except that shielding requirements may differ.

Radwaste incineration technology is being developed at several ERDA sites and is generally at the point of nonradioactive pilot or prototype tests. Technology for removal of most of the surface radioactivity from failed or obsolete equipment (mostly stainless stee1) exists. However, a method that can remove essentially all the surface radioactivity (electropolishing) is under development. 
Size reduction of large, failed or obsolete, contaminated equipment such as stainless steel tanks or glove boxes is desired both for direct volume reduction and to facilitate immersion-type decontamination. Metal cutting technology exists but is generally impractical or awkward for contaminated equipment. Cutting methods being developed or considered include a remote plasma arc torch, an electric arc saw, and explosive cutting.

A special category of waste, HEPA filters, is being compacted at some sites but further development is underway or planned for recovery of $\mathrm{Pu}$ and for improved equipment to separate the filter media from the frames so that the former can be compacted.

Technology is adequate for general trash compaction (drum compactors, balers, etc). Commercially available technology is available for ram compaction and roll flattening.

Some form of immobilization, such as incorporation into a concrete or glass matrix or fusion, may be required for solid wastes such as TRU incinerator ash, fuel hulls (if TRU) and noncombustible TRU scrap, to reduce risks during shipping, handling, and initial storage. Commercial systems exist in the U. S. for immobilizing some radwastes, such as sludges and resins, in concrete; R\&D is being done to adapt such systems to accommodate ashes and other relatively small solids, and to develop technology for concrete immobilization of bulkier solids. Ash vitrification is being considered; only preliminary bench tests have been done in the U. S. A few tests of concrete $\alpha$-radiolysis have been made, and more are planned. Technology for melting irradiated zircaloy hulls into immobile ingots is being actively developed and is near the hot demonstration stage, but economic feasibility is uncertain.

Efficient solid waste management would be greatly enhanced by systems capable of rapidly discriminating at the $10 \mathrm{nCi} \mathrm{TRU} / \mathrm{g}$ level for a variety of wastes and packages. Currently, this is feasible only for low-density TRU wastes, without fission product contamination, in fairly small packages. Such systems are based on passive, low-energy gamma assay. Neutron interrogation systems are being developed which could considerably extend waste monitoring capabilities.

\section{$R \& D$}

The RqQD required for treatment of solid wastes from a thorium or any other nuclear fuel reprocessing plant is going to depend strongly on the acceptance criteria imposed by a federal repository 
to which TRU or other wastes must legally be sent. For example, the Waste Isolation Pilot Plant is currently developing acceptance criteria for ERDA TRU wastes, and the most recent draft (July 1, 1977) limits the combined weights of organics, concrete, steel, and other materials defined as "gas producing" to $10 \%$. This would effectively eliminate from consideration concrete immobilization and, perhaps, steel (or heavy steel) containers. If such a criterion were eventually set up for commercial waste, technology such as melting of metals and incineration-vitrification of all other TRU solid wastes would probably be required. Meanwhile reasonable objectives of volume reduction and immobilization will be pursued.

The on $1 y$ unique R\&D requirements now foreseen for the TFCT Program are:

- Electropolishing - electrolyte treatment and recovery - remova1 of $\mathrm{Th}$ and $\mathrm{U}$ in addition to $\mathrm{Pu}$ contamination.

- Monitoring - The ${ }^{232} \mathrm{U}$ impurity may actually make TRU solid waste monitoring easier, but specific systems will probably have to be developed.

\section{b. Liquid Wastes}

Liquid wastes from thorium processing differ from those originating in $\mathrm{UO}_{2}$ fuel processing primarily in that fluoride and $\mathrm{Th}$ are present in the wastes. The thorium, if present in small amounts, should not cause major difficulties. However, the presence of fluoride would present problems for liquid waste storage and waste solidification. The principal problem would be in handling corrosive fluoride-bearing off-gases from glass making, although there would be other corrosion problems in handling and concentrating the solutions feeding the solidification plant.

If $\mathrm{Pu}$ were sent to the waste solutions, the waste handling process would have to be carefully analyzed for nuclear safety considerations.

Other waste concerns should not differ significantly from those being studied in the AFCT Program. (It is assumed that no substantial dissolution of $\mathrm{Zr}$ hulls will occur, because of the effect on $\mathrm{ThO}_{2}$ dissolution.) 


\section{High Level Liquid Waste (HLLW)}

\section{Status}

HLLW contains the bulk of the fission products and includes those streams which contain traces of plutonium. The streams making up HLLW are acidic and come from solvent extraction. For LWR HLLW, the facilities for handling, storage and solidification have been defined under the AFCT Program. While storage of acid waste is fully demonstrated in Europe, plant scale solidification of HLLW has not been demonstrated. For the thorium fuel cycle, fluorides will likely be required for dissolving. If the plant process parallels that for the AFCT Program, the fluorides will greatly increase equipment costs in dissolving, waste evaporation, off-gas treatment, glass-waste-form production, and possibly first cycle solvent extraction. To ensure low leachability and structure stability, the chemical composition of the glass may need to be adjusted. If the spent fuel elements are declad by chemical means, the waste volume will increase by roughly 6 fold over that for conventional LWR fuel. Alternative storage routes need to be assessed.

\section{$R \& D$}

- Establish composition of HLLW waste expected for the thorium fuel cycle.

- Develop and test hypotheses concerning the impact of thorium cycle waste on equipment and solidification process (denitration, glass composition, etc).

- Assess potential for deactivating the fluorides.

- Determine materials which would provide acceptable equipment life in each process step handling HLLW.

- Assess waste solidification alternatives, and complete technical development of the most promising alternatives.

- Develop analytical methods to monitor corrosion products in HLLW streams and containers (if required). 
Intermediate Level Liquid Waste (ILLW)

Status

ILLW is composed of assorted waste streams from across the plant, i.e., overheads from process stream evaporators, equipment rinses and decontamination solutions, laboratory wastes, etc. The AFCT Program defines methods for treating alkaline, acid and halide bearing wastes. For that program the waste is solidified in cement using a special grout formulated by ORNL. Since the AFCT process was purposely designed for handling a broad range of waste streams, the technology should be directly applicable to a thorium fuel reprocessing plant.

$R \& D$

- Define the expected plant waste streams and compositions.

\section{Decontamination/Decommissioning}

\section{Status}

Nuclear plant decommissioning technology exists and has been applied to several reactors; however, no major chemical separations plant has been decommissioned. Because there are no decommissioning criteria established for fuel reprocessing plants, only general design guidance and decommissioning plans are being developed. Some work is being done to develop specialized techniques and tools such as thermal concrete spallation and remote metal-cutting equipment.

$R \& D$

No RED unique to a thorium fuel reprocessing plant is foreseen until or unless quantitative decommissioning criteria are established. 


\section{Environmental and Safety Studies}

\section{Programmatic Environmental Statement}

A programmatic environmental impact statement will be prepared on thermal reactor/thorium fuel cycles that show promise of meeting national nonproliferation objectives. Uranium-based fuel cycles under consideration in the AFCT Program will also be addressed in this EIS. The programmatic environmental statement will demonstrate ERDA compliance with the National Environmental Policy Act and will be useful to ERDA by defining environmental effects of alternative fuel cycles that reduce the risk of nuclear weapons proliferation.

The environmental statement will include a description of model facilities and processes required for each fuel cycle, including development of source terms and a discussion of proliferation-resistant aspects. Environmental effects will be evaluated for each model facility at a hypothetical site.

\section{Regulatory Aspects}

NRC guidelines and other applicable regulations will be incorporated into the program. In preparation for the possible utilization of thorium fuel cycle technologies, technical and environmental information required for licensing of facilities will be identified and developed.

\section{Environmental Effects}

The objectives of the Environmental Effects Program for the TFCT Program are basically the same as the objectives of the present AFCT Environmental Effects Program. This program (AFCT) will provide state-of-the-art methods for performing environmental dose consequence assessments from the releases from an AFCT reprocessing complex to regional, U. S. and global populations. These types of calculations will be done for several different regions of the United States. The broad objective applies to al1 participating laboratories who are contributing their own expertise on items ranging from source terms to agricultural food chains.

The AFCT Program specifically is one of planning and coordination of the inter-laboratory effort, performing laboratory studies on possible pollutants from tritium removal processes, performing regional, U.S., and global dose assessments using data 
from other laboratories and preparing an inter-laboratory report on the environmental effects of siting an AFCT complex in different regions of the United States.

The methodologies, data and mathematical models used in the AFCT Program will be extended to include those releases to the environment of pollutants from the thorium fuel cycle not presently covered in the present AFCT Program.

In the longer term, SRL computer systems support will be required to develop environmental data bases and simulation methodologies employed at various other laboratories in order to improve the generic assessment of environmental effects and to support the AFCT program as it evolves towards a reference design.

\section{Economics}

\section{Complete Fuel Cycle Studies}

In support of the LWR uranium fuel recycle program, preliminary economic studies of the complete fuel cycle ${ }^{2}$ were made. The purpose of these economic studies was to provide part of the initial justification for the program. In the course of these studies, a computer code called ENP was written to assist in answering detailed ERDA questions about the uranium cycle. Another computer code, NUFACTS, ${ }^{3}$ developed by Battelle-Columbus, is a more general code than ENP; NUFACTS can consider a wide variety of reactors and fuels, including thorium, but in less detail than the ENP code.

Preliminary economic studies for the thorium fuel cycle will be made using NUFACTS modified somewhat if necessary. This code can also be used for estimating system requirements for uranium and thorium, and separative work.

\section{Processing Plant Studies}

Processing of irradiated thorium fue 1 assemblies is sufficiently different from processing of irradiated uranium fuel assemblies that the reprocessing plant costs may be significantly different. For example, uranium concentrations in the solvent stream during Purex processing typically run up to $0.4 \mathrm{M}$ whereas during Thorex processing the thorium concentration in the solvent is usually maintained below $0.2 \mathrm{M}$ to prevent formation of a second phase. Processing of thorium at rates equivalent to uranium requires higher solvent flow rates with the Thorex process and therefore larger reprocessing equipment. 
Other process differences that will probably impact on plant economics are: (1) the use of fluoride for $\mathrm{ThO}_{2}$ dissolution will affect equipment design from dissolution through waste solidification; (2) the presence of zirconium may reduce the $\mathrm{ThO}_{2}$ dissolution rate, thus requiring additional dissolvers; (3) the removal of tritium may require prior size reduction of fuel; and, (4) fuel dejacketing in order to size reduce $\mathrm{ThO}_{2}$ and to minimize the effect of zirconium on dissolution rates.

A decision must be made as to what to do with the plutonium produced in the denatured uranium. Current requirements are that no separate stream of pure plutonium be produced (except perhaps in a secure area). Therefore, plutonium would presumably be retained with a small portion of the thorium stream and recycled into new fue1. With either a pure $\mathrm{Pu}$ stream or a $\mathrm{Pu} / \mathrm{Th}$ stream, additional costs would probably be incurred in providing for partitioning and separate handling. Alternatively, plutonium could conceivably be rejected to the high level waste from the recovery process. The presence of these fairly large quantities of plutonium in the waste would probably affect the design and cost of the waste solidification process.

The fissile concentration of recycled fuel from the uranium fuel cycle is maintained by increasing the plutonium concentration from the $1 \%$ value in spent fue 1 to $3-5 \%$ in the mixed oxide fue 1 (the excess uranium is re-enriched at the gaseous diffusion plant). Enrichment of recycled denatured uranium from the thorium cycle in the gaseous diffusion plant is unacceptable because of the ${ }^{232} \mathrm{U}$ content which would contaminate the facility, and because of the large inventory and thus long holdup of ${ }^{23}{ }^{3} \mathrm{U}$ in such a plant. Some method must be devised to re-enrich the spent fuel from the thorium cycle (small centrifuge plant or blending either in a secure energy center or in a secure uranium enrichment center), and the cost of re-enrichment must be included in the fuel cost.

\section{E. Proliferation and Safeguards}

The impetus for the AFCT/TFCT Programs is the desire to create a reactor fuel cycle that is not easily adapted to nuclear weapon production. Such a cycle would presumably reduce the internal safeguards threat by terrorist organizations and the international threat of nuclear arms proliferation. The reactor fuel for TFCT is ${ }^{235} \mathrm{U}$ and/or ${ }^{233} \mathrm{U}$ "denatured" (made unsuitable for weapons without isotope enrichment) by adding ${ }^{238} \mathrm{U}$. The purpose of the proliferation and safeguards section of the TFCT Program is to determine (1) what constitutes "denaturing" for fuel streams leaving secure areas, (2) the effort in time, capital, and personnel required to reverse the denaturing 
process, (3) the residual degree of safeguards controls necessary to protect all parts of the fuel cycle, and (4) the comparative safeguards and proliferation levels of TFCT and AFCT fuel cycles.

Assurance that all streams in the fuel cycle are proliferationresistant can be achieved, for example, by imposing three constraints on the choice of fuel cycles: uranium feed to the cycle is limited to an enrichment of $20 \%{ }^{235} \mathrm{U}, \mathrm{Pu}$ may not be separated from fission products (except perhaps in a secure area), and ${ }^{238} U$ is intimately mixed with all thorium before (or after) irradiation. The evaluation of the effort required to reverse the denaturing process of various streams will examine state-of-the art methods of isotopic separation and project future capabilities in this technology. Safeguards controls that would be necessary for thorium fuel cycles will be based on safeguards criteria developed at Sandia and Los Alamos Laboratories and included in the Technical Data Summary for the Design Integration Study. The safeguards and proliferation comparison of $\mathrm{Th} /{ }^{2{ }^{3}} \mathrm{U}$ and $\mathrm{U} / \mathrm{Pu}$ fuel cycles will be based on the design studies for the fuel cycles developed by the Du Pont Engineering Department.

\section{F. Corrosion Studies}

Much of the equipment included in the TFCT conceptual design will parallel similar equipment developed for the AFCT conceptual design. However, the hot nitric acid containing the fluoride ion used for TFCT will significantly aggravate the corrosion of such equipment as dissolvers, nitric acid recovery, evaporators, and waste handling. Special alloys will be needed. Fabrication, welding, and stress relief techniques may be specified for select equipment. Laboratory tests will be required to effectively screen materials for longer term tests.

\section{G. Design Integration Study}

Design integration studies will be performed to appraise costs for facilities for the recycle of spent thorium LWR fuel and to identify gaps in available technology and suggest areas for further R\&D. Part of the program will be to develop and document the technical basis and conceptual design for all buildings and hardware for a fuel processing complex. The complex is to produce recycle materials, refabricated fuel, and packaged wastes which meet all federal and local regulations. The remainder of the program to assess alternative systems will parallel and borrow from the AFCT Program for conventional LWR fuel. Prime considerations are:

- Minimize potential contributions to nuclear weapons proliferation. 
- Maximize international nuclear materials safeguards and control.

This task will be performed by SRL, SRP and the Du Pont Engineering Department. SRL will coordinate the reprocessing RED effort and manage the input from other ERDA contractors who are to provide basic data support.

\section{H. Development Program Schedule}

The TFCT Program schedule is shown in Figure 1. The R\&D program will be initiated at the beginning of FY-1978. The major emphasis of the RGD effort from October 1977 through FY-1980 will be in support of the Design Integration Studies. Subsequent to FY-1980, the R\&D emphasis will shift toward development of improved and alternative processes, and to provide information required for licensing or environmental assessments.

Preliminary Technica1 Data Summaries (TDS) will be complete by about July 1978 so that a Scope of Work can be completed by the Engineering Department by October 1979. This will allow for a Preliminary Venture Guidance Appraisal (VGA)* in February 1980 and a final VGA in February 1981. The Design Integration Studies will begin in the 1atter part of FY-1978, which will allow 6-9 months for preparation of preliminary technical data summaries.

Initial studies are required to examine numerous reactor and fuel reprocessing scenarios and determine alternatives that provide significant advantages in terms of economics, resource utilization, and proliferation resistance. These studies will be performed in early FY-1978 to define fuel form, enrichment range, plant throughput, cooling times, etc.

\section{REFERENCES}

1. Progrom Plan for Research and Development in Support of LWR Fuel Recycle. USERDA Report DPST-75-517, E. I. du Pont de Nemours and Co., Savannah River Laboratory, Aiken, SC (1975).

2. Advanced Operational Planning. Assessment of Nuclear Fuel Reprocessing. USERDA Report DPST-75-448, E. I. du Pont de Nemours and Co., Savannah River Laboratory, Aiken, SC (1975).

3. Triplett, M. B. "NUFACTS - Simulation of Nuclear Power Economy," Nuclear Technology (to be published).

* VGA - A cost estimate based on preliminary design information which may be used for purposes other than appropriation. 


\section{FIGURE I}

Research and Development
Initial Studies
Process Studies
Improved Studies
Design Integration Studies
Preliminary TDS Complete (7/78)
Assessment of Data (11/78)
Scope of Work (10/79)
Preliminary VGA (2/80)
Final Basic Data (4/80)
Final Scope of Work (10/80)
Final VGA (2/81)
Final Report (8/81)


APPENDIX

\section{BACKGROUND INFORMATION}

In this appendix, information is provided that is peripheral to the chemical processing work that will be managed by SRL; however, the information is included because of its importance to the decisions that must be made which pertain to the entire thorium fuel cycle.

First, thermal reactors whose fuels might be processed aqueously are briefly described. The HTGR is included even through chemical processing of HTGR fuel is an ORNL responsibility.

A general discussion is then given of thermal reactor fuel cycle alternatives. The use of thorium can have a significant near-term impact on the nuclear power only if the reactor that is used is the current PWR or BWR design. The problems of converting the LWR fuel cycle from uranium fuels to thorium fuels are next described. Finally, a brief discussion is given of uranium and thorium requirements and of the availability of these fuels.

\section{A. Thermal Reactors and Their Fuels}

\section{1. $L W R$}

The only reactor designs that are presently commercialized in the United States are PWR's (Pressurized Water Reactors) and BWR's (Boiling Water Reactors). Together they are referred to as LWR's (Light Water Reactors). Current and future designs operate at 1000-2000 MWe. There are presently about 50 GWe of installed capacity; estimated future capacities are about $200 \mathrm{GWe}$ in 1990 and about 400 GWe in 2000 .

LWR's use fuel consisting of columns of pellets of $\mathrm{UO}_{2}$ enriched to about $3 \%{ }^{235} \mathrm{U}$ in zircaloy tubes. In the PWR's the fuel inventory is 80 metric tons of uranium of which one-third is replaced each year. In the BWR's the fuel inventory is 105 metric tons of uranium of which one-fourth is replaced per year. Natural uranium mining requirements are estimated at about 195-220 metric tons/GWe/yr per reactor. ${ }^{1,2}$ Average fuel exposures are projected to be about 30,000 MWD/metric ton. Currently, the time between the decision by a utility to build an LWR and its initial operation is somewhat over 10 years. 


\section{HWR}

The CANDU reactor is a Heavy Water Reactor (HWR) design currently being built in Canada. The coolant used is heavy water contained at high pressure in zircaloy pressure tubes while the moderator is heavy water at low pressure. Current designs operate at about 800 MWe.

CANDU fuel loading is about 150 metric tons of natural $\mathrm{UO}_{2}$ clad in zircaloy. Annual mining requirements are estimated at about 130-170 metric tons/GWe/reactor. ${ }^{1,2}$ Average fuel exposure is about 10,000 MWD/metric ton.

There are licensing problems involved with introducing the CANDU's into the U. $S$. These center on the use of pressure tubes rather than a pressure vessel and the novel containment method used by the Canadians. In the normal course of events it is unlikely that NRC approval could be obtained without an extensive study. Even if a decision were made immediately to use HWR's in the United States, the first reactors could not be operating before the mid 1990's.

\section{SSCR}

In thermal converter reactors, less fissile isotopes are produced than are burned and the reactivity decreases with exposure. To achieve long exposures, excess fissile isotopes are introduced initially. In LWR's, burnable poison is added initially to control the associated excess reactivity and the neutrons absorbed in the poisons are wasted.

An alternative to the use of burnable poisons is provided by the Spectral Shift Control Reactor (SSCR). Some of the light water in the reactor is replaced by heavy water and this increases resonance absorption in fertile isotopes; thus, extra fissile isotopes are produced. As exposure proceeds, the fraction of heavy water is reduced. Typical heavy water concentrations are about $60 \mathrm{~mol} \%$ at the beginning and about $10 \mathrm{~mol} \%$ at the end of core life. The improved conversion ratio decreases mining and separative work requirements. SSCR fuel would be similar to LWR fue 1 .

This concept has not been developed because the conversion ratio improvement has not been considered important enough to compensate for the extra complications introduced by the $\mathrm{D}_{2} \mathrm{O}$, i.e., $\mathrm{D}_{2} \mathrm{O}$ cost, distillation plant for reconstituting $\mathrm{D}_{2} \mathrm{O}$, tritium leakage problems, etc. 
The use of a "stowaway" fuel cycle may change the economics of this system to make the higher conversion ratio more attractive and will be one of the factors that must be considered in this study.

It is unlikely that existing LWR's could be converted to Spectral Shift type operation although the manufacture of these reactors would be quite similar to the LWR's.

4. $H T G R$

The High Temperature Gas-cooled Reactor (HTGR) is completely different from the water-cooled reactors previously described.

The reactor coolant is helium at a pressure of 700 psia contained in a prestressed concrete vessel. The reactor is graphite moderated and reflected and has thorium in the fuel cycle. Fuel elements are stacked together vertically and horizontally to form the entire core, so no separate moderator or internal structure is required.

Within a fuel element the fuel is contained in particles of $\mathrm{UC}_{2}$ (or $\mathrm{UO}_{2}$ ) coated with two layers of pyrolytic carbon and then bonded with low-density carbon into "fuel sticks" about 0.45 in. in diameter. The fuel particles are of two types: a fertile particle containing the thorium and the recycled uranium (mostly ${ }^{233} \mathrm{U}$ ), and a fissile particle containing makeup uranium fully enriched in ${ }^{235} \mathrm{U}$. The fertile particle has a kernel diameter of $350 \mu$ and a coating thickness of $130 \mu$, while the fissile particle has a kernel diameter of $150 \mu$ and a coating thickness of $150 \mu$. The use of two different particles permits separation of the particle types during reprocessing so that the

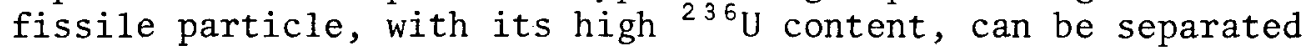
and thus not included in the material to be recycled.

Only one HTGR, the demonstration Fort St. Vrain reactor (330 $\mathrm{MWe}$ ), is currently operating in the U. S. No other reactors are presently planned. Annual uranium mining requirements are estimated to be $100-158 \mathrm{MT} / \mathrm{GWe} /$ reactor. ${ }^{1,2}$

One possible design for a full power HTGR (1000 MWe) requires an annual shutdown for refueling and operates on a four-year refueling cycle. Another design employs continuous on-1ine refueling.

Possible commercialization schedule studies remain to be developed but the first reactors would not be expected prior to the mid 1990's. 


\section{B. Fuel Cycle Alternatives}

The thorium fuel cycle is not, in and of itself, an answer to the problem of proliferation of nuclear weapons. Indeed the fissile isotope produced in irradiated thorium, ${ }^{23}{ }^{3} \mathrm{U}$, is equally effective as a nuclear weapon material as the plutonium produced in the uranium fuel cycle. In an attempt to reduce the weapons potential of ${ }^{23} \mathrm{U}$, proposals have been made to "denature" ${ }^{23}{ }^{3} \mathrm{U}$ with ${ }^{238} \mathrm{U}$. By maintaining a ${ }^{23} \mathrm{U}$ enrichment of about $12 \%$, this isotope is reduced in weapons potential to that of $20 \%$ enriched ${ }^{2}{ }^{35} \mathrm{U}$. This solution, however, creates a problem of its own; when "denatured" ${ }^{23} \mathrm{U}$ (or ${ }^{2{ }^{3}} \mathrm{U}$ ) is used as a reactor fuel, plutonium is produced in the ${ }^{238} \mathrm{U}$ denaturant at a rate about $20-30 \%$ of that in the uranium cycle. Studies of thorium fuel cycles using denatured fissile uranium isotopes must address the problem of plutonium recycle or disposal.

Another problem that must be solved in the thorium cycle is the re-enrichment of spent fuel when that fuel is denatured uranium. In the uranium fuel cycle, spent fuel is recycled to a gaseous diffusion plant (GDP) for re-enrichment; with a thorium cycle, return of uranium to an enrichment plant is not acceptable unless that plant is designed specifically to cope with highly radioactive uranium (caused by ${ }^{232} \mathrm{U}$ ).

Current thermal reactor designs use a fuel containing homogeneous mixtures of uranium, uranium-plutonium, or uraniumthorium. With a homogeneous uranium-thorium fuel, recovered uranium will require re-enrichment, probably by blending, which will increase the total uranium in recycle if the blend material is denatured. Slight growth of the recycle stockpile is acceptable in an expanding industry, however, at equilibrium some of the stockpile could not be used resulting in a loss of some of the ${ }^{2}{ }^{3} \mathrm{U}$.

An alternate mode of reactor fueling is the use of a seed and blanket. By seeding with enriched ${ }^{23} \mathrm{U}$ in a separately dischargeable fuel assembly, a product could be recovered that is compatible with a re-enrichment in a GDP. The blanket thorium assemblies, containing small quantities of ${ }^{238} \mathrm{U}$ (and possibly ${ }^{2}{ }^{5} \mathrm{U}$ ) and ${ }^{2}{ }^{3} \mathrm{U}$ produced from thorium irradiation, could be reworked separately as necessary to remove fission products. This material would be returned to the reactor without enrichment.

Several alternative cycles can be derived from the homogeneous and seed-blanket fuel concepts. These alternatives are as follows:

1. Homogeneous fuel with $\mathrm{U}-\mathrm{Pu}-\mathrm{Th}$ recycle. 
2. Uranium seed-thorium blanket with separate recycle of the seed and blanket.

3. Uranium and thorium blanket with seed recycle and blanket stowaway.

4. Uranium and thorium blanket with blanket recycle and seed stowaway.

5. Homogeneous fuel - stowaway.

6. Uranium seed - thorium blanket - stowaway.

(Alternatives 5 and 6 apply to economic analysis only and would be needed for comparison with stowaway analysis of uranium fuels.) Each of the above alternatives could be expanded to include metal or oxide fuels and stainless steel or zirconium cladding.

Some of the factors which must be considered in designing the lattice are listed below:

1. The effective macroscopic cross section of $\mathrm{ThO}_{2}$ is higher than that of $\mathrm{UO}_{2}$. This means that a higher ${ }^{235} \mathrm{U}$ or ${ }^{23}{ }^{3} \mathrm{U}$ fraction is required in $\mathrm{ThO}_{2}$ than in $\mathrm{UO}_{2}$ and the total core inventory of fissile material will be larger.

2. Both ${ }^{23} \mathrm{U}$ and ${ }^{232} \mathrm{Th}$ cross sections are less affected by spectrum changes than are ${ }^{238} \mathrm{U}$ and ${ }^{239} \mathrm{Pu}$ cross sections and the delayed neutron fraction of ${ }^{23}{ }^{3} \mathrm{U}$ is much smaller than for ${ }^{235} \mathrm{U}$ and ${ }^{239} \mathrm{Pu}$. These factors will affect coefficients and thus transient responses.

3. The burnup to decay ratio for ${ }^{233} \mathrm{~Pa}$ (the decay precursor of ${ }^{23} \mathrm{U}$ ) is much larger than that for ${ }^{239} \mathrm{~Np}$ (the decay precursor of ${ }^{239} \mathrm{Pu}$ ) and the resonance-to-thermal absorption cross section ratio of ${ }^{23} \mathrm{~Pa}$ is much larger than the ratio for ${ }^{23}{ }^{3} \mathrm{U}$ or ${ }^{235} \mathrm{U}$. Therefore, significant amounts of ${ }^{2{ }^{3}} \mathrm{~Pa}$ can be converted to ${ }^{234} \mathrm{U}$ before decay and any fuel configuration which reduces the flux and particularly the resonance flux in the ${ }^{233} \mathrm{~Pa}$ will improve the neutron economy. This could be done with a seed and blanket arrangement.

Consideration may have to be given to processing thorium fuel from Heavy water Reactors (HWR) at some later time. Fuel designed for use in HWR has a lower enrichment than do LWR fuels and is run to a lower exposure with a resulting higher throughput. In addition the fuel tube and bundle sizes will be different.

Remote fabrication and separations facilities should be designed to handle the range of assembly sizes for either a HWR or LWR lattice. 


\section{Fuel Material}

Thorium oxide and thorium-uranium oxide fuels have been extensively studied and feasibility for reactor irradiation has been established.

Higher conversion ratios (up to $10 \%$ ) could be achieved with metal fuel and it is possible that fabrication cost savings could be achieved by the coextrusion of metal fuel and zircaloy cladding.

Metallic uranium fuels have not been seriously considered for LWR's because of dimensional instability and the possibility of metal-water reactions. Thorium and thorium-uranium mixtures have significantly better properties on both counts. In addition, the powdering problems associated with oxides would be avoided.

Additional development work on reprocessing and the more difficult fabrication of metal fuel must be weighed against the advantages described above.

\section{Cladding}

Zirconium alloy cladding provides improved neutron economy relative to stainless steel.

Separations problems associated with dissolving thorium in the presence of zirconium will require additional development

work. A larger waste volume would be associated with $z$ irconium.

The economic benefits of zirconium must be weighed against the increased development costs and larger waste volumes.

\section{Fuel Material Form}

Fabrication of ${ }^{233} \mathrm{U}$ fuel must be done remotely due to the presence of ${ }^{232} \mathrm{U}$. Pellet production, used for the uranium fuel cycle, involves powder handling which results in dusting and potentially high operator doses as well as problems with equipment decontamination and material accountability. For these reasons, powder pellet fabrication may not be feasible with ${ }^{23} \mathrm{U}$ fuel.

Techniques for remotely preparing and transferring mixed oxide sol-gel microspheres and for loading them into fuel pins have been developed for the HTGR and LMFBR programs. Limited irradiation data indicate the performance of sphere-pac fuel may be superior to pellet fuels, but extensive testing of irradiated fuels will be required before either form can be proposed for commercial use. 
Further studies of production, irradiation behavior and separation of the sol-gel material would be required before a final decision on the process is made.

\section{LWR Conversion to Thorium Cycles}

An important factor in the selection of the optimum $\mathrm{Th}^{23{ }^{3} \mathrm{U}}$ fue1 cycle will be the impact on existing LWR fuel cycle systems. Four broad areas of the existing system will be affected: the feed supply area encompassing the uranium mining, milling, and enrichment industry, the fuel management area representing the current fuel fabrication industry with its stockpiles of feed and component parts, the reactor facilities themselves, and the regulatory interests currently responsible for the safety and environmental impact of the nuclear power industry. Some of the considerations in each of these areas that have to be resolved are discussed below.

\section{Feed Supply}

The primary consideration in this area is compatibility of the $T h / U$ fuel cycle requirements with the capacity of the present uranium mining, milling, and enrichment industry. It is expected that $\mathrm{Th} / \mathrm{U}$ fuel cycle requirements for uranium will exceed $\mathrm{U} / \mathrm{Pu}$ fuel cycle requirements early in the transition period; 1ater, at equilibrium, the requirements will be lower, particularly if plutonium is recycled rather than discarded. Hence, it will be necessary to balance the expected gains from conversion to a $\mathrm{Th} /{ }^{233} \mathrm{U}$ cycle with capital requirements for new capacity. Other variables that will be significant in this area include the cost of uranium feed and separative work and the tails assay of enrichment plants.

\section{Fuel Management}

The nuclear fuel element manufacturing industry is presently equipped to produce very specific fuel types. Conversion to a $\mathrm{Th} /{ }^{2{ }^{3}} \mathrm{U}$ fuel cycle will require a substantial rearrangement. Areas that will be different include fuel element design, feed material, blending requirements, and components. In addition, safeguards requirements, and possibly quality control standards, will be different. Thus, in general terms, the change in fuel cycles will require a substantial fuel element design effort, a refitting of current equipment, and most likely a capital expansion of the current fuel manufacturing industry. 


\section{Reactor Facilities}

A basic requirement of $\mathrm{Th} /{ }^{23} \mathrm{U}$ fuel cycle is that it be compatible with existing BWR and PWR systems. Nevertheless, substantial modifications to reactor complexes will be necessary. These include adapting fuel receiving areas to handling the new fuel elements, increased radiation levels, modifications to sensing and control systems to reflect the different nuclear and engineering characteristics, different operating schedules for shutdowns and fuel replacement, and appropriate revisions to normal and emergency operating procedures.

A significant input to the program for assessing these modifications will be the experience gained in converting the Shippingport reactor to a Th/ ${ }^{23} \mathrm{U}$ system. The LWBR Program for this conversion is described in References 3 and 4 . In the TFCT Program, however, the reactor loadings will be different than for the LWBR concept. The LWBR Program was directed towards developing a $\mathrm{Th} /{ }^{2{ }^{3}} \mathrm{U}$ breeder fuel cycle. The objective of the TFCT Program is to decrease the likelihood of international nuclear proliferation by developing a "denatured" reactor fuel, in this case ${ }^{23} \mathrm{U}$ denatured by ${ }^{238} \mathrm{U}$. Thus, the reactor fuel elements will contain a mixture of $\mathrm{Th},{ }^{235} \mathrm{U}$, and ${ }^{238} \mathrm{U}$ initially, with increasing amounts of ${ }^{23} \mathrm{U}$ and proportionately decreasing amounts of ${ }^{235} \mathrm{U}$ as the fuel mixture is recycled.

\section{Regulatory Modifications}

Reactor operation with $\mathrm{Th} /{ }^{23{ }^{3}} \mathrm{U}$ components represents a significant departure from current modes of operation. It is anticipated, therefore, that appendices to operating licenses and environmental statements will be required. The bases for these will be, primarily, information produced as part of the TFCT Program. The goal will be to develop a generic information base broad enough to obtain standardization of licensing approval. This will necessitate a review of the current licensing process to compile the information required.

A similar process will be required for the fuel manufacturing industry but the magnitude of effort will be less than for reactor operation.

\section{Resource Requirements and Supply}

One reason advanced for using thorium is that there is several times as much thorium as uranium in the earth's crust. However, thorium is a fertile material only and there is enough fertile uranium to last hundreds of years in a breeder economy. 
There is a potential shortage of fissile isotopes because the only one naturally available is ${ }^{23} \mathrm{U}$. In the early stages of a shift from uranium to thorium, the fissile isotope is ${ }^{235} \mathrm{U}$ and the requirements for natural uranium as a source of this ${ }^{235} \mathrm{U}$ are increased relative to the uranium cycle. However, in later stages of the thorium cycle, some of the fissile isotope can be ${ }^{233} \mathrm{U}$ that is recycled with a resultant increase in the conversion ratio and a decrease in uranium requirements. This increase in conversion ratio may be significant only if the fissile uranium is not denatured or if the plutonium produced as a result of denaturing is also recycled.

Although requirements for uranium may increase in switching to a thorium cycle, requirements for thorium are not necessarily very large. It is only necessary to fill the thorium cycle pipe line and to make up for minor thorium burnup and losses. If enough inexpensive thorium is available, consideration can be given, on an economic basis, to using new thorium rather than recycled thorium in subsequent loads.

Current ERDA estimates are that 3.7 million tons of $\mathrm{U}_{3} \mathrm{O}_{8}$ are economically recoverable domestically based upon a preliminary report, GJO-111(76), from the Natural Uranium Resource Evaluation (NURE) program. A much better assessment of domestic uranium and thorium resources is expected in 1981 as a result of continuing NURE program efforts.

Current data on domestic thorium resources are even less certain than those for uranium. A 1974 compilation by M. H. Staat ${ }^{5}$ shows about 0.8 million tons of $\mathrm{ThO}_{2}$ as identified resources, but two-thirds of this is shown as inferred rather than demonstrated. Much larger tonnages are shown in the hypothetical and speculative categories, but these amounts are associated with low grade $\left(<100 \mathrm{ppm} \mathrm{ThO}_{2}\right)$ igneous rocks. ERDA has requested USGS to upgrade these estimates to approach the level of validity of the above mentioned preliminary report. The new USGS report is expected in April 1978. 


\section{REFERENCES}

1. ORNL/TM 5565, January 1977.

2. Science, Vo1. 196, p 285, April 15, 1977.

3. ERDA-1541, Environmental Statement - Light Water Breeder Reactor Progrom, July 1975.

4. Shippingport Atomic Power Station, Safety Analysis Report for the Light Water Breeder Reactor, U. S. Government Printing office, 1975-603-071/0863.

5. M. H. Staatz, USGS Open-File Report 76-690, 1971. 